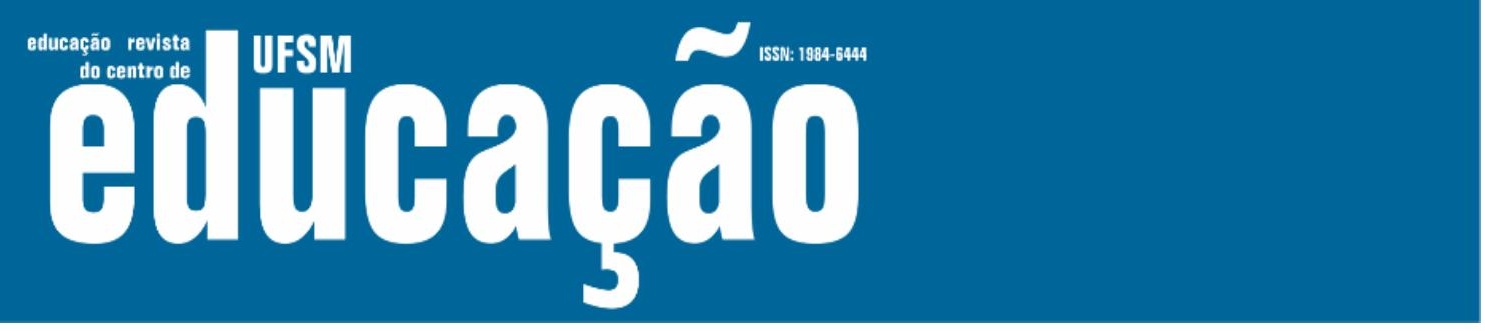

ISSN: 1984-6444 | http://dx.doi.org/10.5902/1984644435702

\title{
As avaliações em larga escala como dispositivo do poder disciplinar e da biopolítica
}

\section{Large-scale evaluations as a biopolitical and disciplinary power device}

\section{Sirley Lizott Tedeschi}

Professora doutora na Universidade Estadual de Mato Grosso do Sul, Dourados, Mato Grosso do Sul, Brasil.

tedeschils@gmail.com - http://orcid.org/0000-0002-4557-8282

Ruth Pavan

Professora doutora na Universidade Católica Dom Bosco, Campo Grande, Mato Grosso do Sul, Brasil. ruth@ucdb.br - http://orcid.org/0000-0001-8979-1125

Recebido em 19 de novembro de 2019

Aprovado em 25 de maio de 2020

Publicado em 10 de agosto de 2020

\section{RESUMO}

Neste artigo, discutimos as avaliações em larga escala. A análise é fruto de pesquisa realizada por meio de entrevista semiestruturada com professores/as que atuam do $6^{\circ}$ ao $9^{\circ}$ ano do Ensino Fundamental em uma escola pública estadual com alto Índice de Desenvolvimento da Educação Básica (IDEB). Para a análise dos enunciados dos/as professores/as, aproximamo-nos dos estudos pós-estruturalistas. Problematizamos, em um primeiro momento, as avaliações em larga escala e a pretensão de se colocarem como uma das "verdades" da educação na atualidade e de medirem a "qualidade" da educação. Em um segundo momento, mostramos as avaliações em larga escala como um dispositivo do poder disciplinar e da biopolítica. Ao adotarem procedimentos do poder disciplinar e da biopolítica para o controle e normalização dos sujeitos escolares, essas avaliações forçam uma padronização curricular e deparam-se com movimentos de resistência de professores/as e alunos/as, que potencializam outros modos de pensar a avaliação, o currículo e os processos educacionais no contexto escolar.

Palavras-chave: Avaliação em Larga Escala; Currículo; Poder.

\section{ABSTRACT}

In this paper, we address large-scale evaluations. This analysis has stemmed from a research involving a semi-structured interview with $6^{\text {th }} 9^{\text {th }}$ grade teachers of a public state school with high Basic Education Development Index (IDEB). In order to analyze the teachers' statements, we resorted to post-structuralist studies. Firstly, we problematize the large-scale evaluations and their pretension of both being assumed 


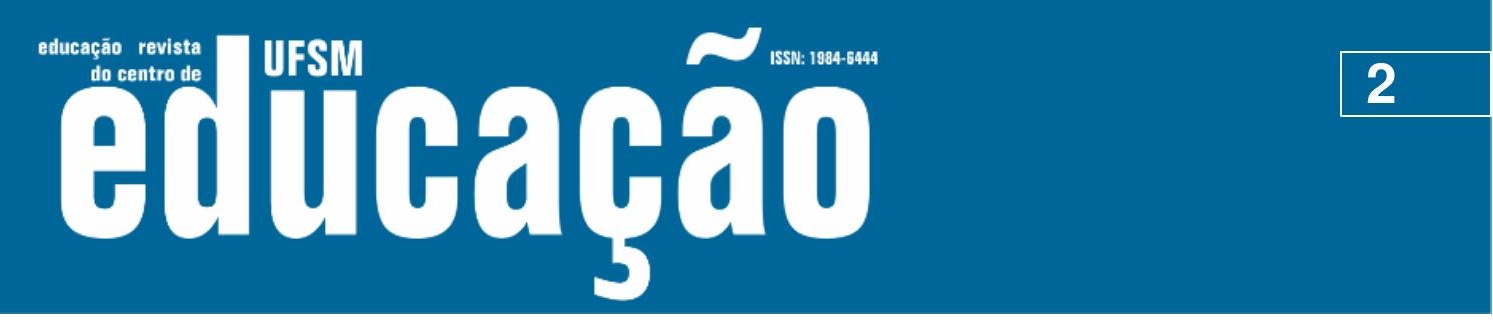

ISSN: 1984-6444 | http://dx.doi.org/10.5902/1984644435702

as one of the current education "truths" and measuring the education "quality". Secondly, we show the large-scale evaluations as a disciplinary and biopolitical power device. By adopting procedures of disciplinary power and biopolitics for controlling and normalizing the school subjects, these evaluations have forced the curriculum standardization and faced teachers and students' resistance movements, which potentialize other ways of thinking about evaluation, curriculum and educational processes in the school context.

Keywords: Large-scale evaluation; Curriculum; Power.

\section{Introdução}

A escola estadual na qual foi aplicada a pesquisa desenvolvida no presente artigo oferece o ensino fundamental do $1^{\circ}$ ao 9ํaㅅ e está localizada na Região Centro-Oeste do país. Em 2011, 2013 e 2015, ficou entre os primeiros lugares nos rankings de seu estado, conforme o Índice de Desenvolvimento da Educação Básica (IDEB). Esse fato trouxe muito contentamento, tanto da direção da escola e da coordenação pedagógica, quanto dos/as professores/as e dos pais. Os/as professores/as sugeriram fazer uma faixa para ser colocada na frente da escola, com o intuito de divulgar para a comunidade a "qualidade da educação" da instituição. Sugeriram, inclusive, que todos/as os/as professores/as deveriam ser premiados/as; afinal, estavam merecendo. Foram entrevistados/as nove professores/as dessa escola que lecionam do 6ํㅜ ao $9^{\circ}$ ano do Ensino Fundamental e que atuam nas diversas áreas de conhecimento. Porém, faremos alusão somente aos enunciados de seis professores/as pois os enunciados dos/das três professores/as não citados/as estão contemplados nos enunciados citados; para preservar o anonimato, utilizaremos nomes fictícios sempre que nos referirmos a eles/as e não indicaremos o índice, nem o lugar na classificação.

Com Traversini (2013), pensamos que tensionar esse modelo de avaliação e os índices produzidos em um contexto em que, de certa forma, o empenho da escola e dos/as professores/as ainda é no sentido de atingi-los parece ser inoportuno ou impróprio.

Neste artigo, aproximamo-nos dos estudos pós-estruturalistas e analisamos enunciados obtidos por meio de entrevista semiestruturada com professores/as de 


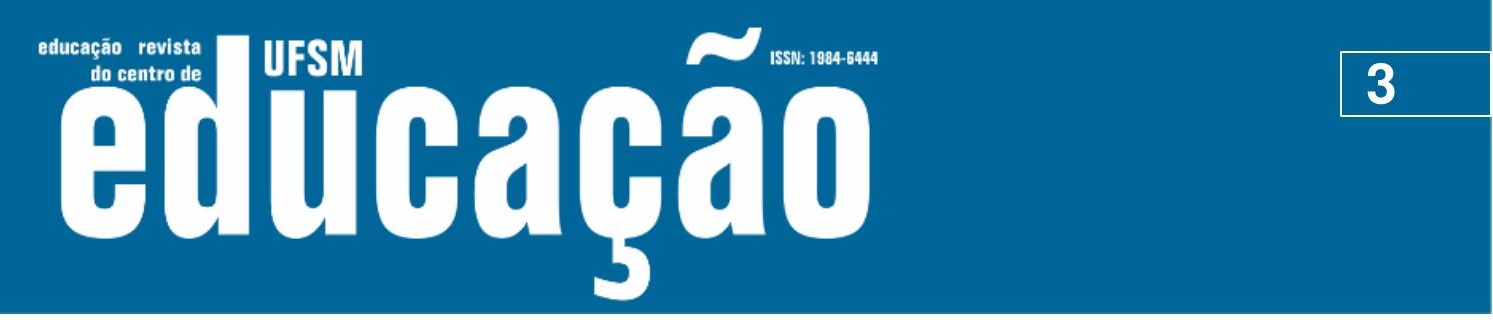

ISSN: 1984-6444 | http://dx.doi.org/10.5902/1984644435702

diversas áreas do conhecimento que atuam do 6ำ ao 9ํano do Ensino Fundamental em uma escola pública estadual com alto IDEB. Problematizamos, em um primeiro momento, as avaliações em larga escala e a pretensão de colocarem-se como uma das "verdades" da educação na atualidade e de medirem a "qualidade" da educação. Em um segundo momento, mostramos as avaliações em larga escala como um dispositivo do poder disciplinar e da biopolítica. Ao adotarem procedimentos do poder disciplinar e da biopolítica para o controle e normalização dos sujeitos escolares, essas avaliações forçam uma padronização curricular e deparam-se com movimentos de resistência de professores/as e alunos/as a esses mecanismos de poder. Os movimentos de resistência que os/as professores/as e aluno/as colocam em ação na escola potencializam outros modos de pensar a avaliação, o currículo e os processos educacionais no contexto escolar.

\section{É preciso pensar além daquilo que é dado, ou: problematizando as avaliações em larga escala}

Iniciamos 0 item citando alguns enunciados de professores/as entrevistados/as. A professora Verônica, ao referir-se à avaliação em larga escala, diz que é "uma avaliação muito boa; os professores fazem um trabalho muito bonito". Ela afirma: "a escola tem toda uma preocupação, e a gente se preocupa também. Se o índice abaixa, aí a preocupação aumenta. Nós não podemos deixar que esse índice caia, nós temos que estar sempre elevando". O professor Pedro diz que o fato de a escola ter obtido alto IDEB é um incentivo para os/as professores/as: "eles sentem que o trabalho deles está tendo resultado, então, parece que também tem um retorno gratificante para o professor. Então, acho positivo, nada de negativo".

Os enunciados desse professor e dessa professora mostram que é muito difícil pensar além daquilo que é dado. Sobretudo, "quando isso é visto como fruto de um desejo compartilhado pelo qual se lutou lado a lado contra tudo o que se opunha a sua realização" (LARA, 2003, p. 11). Por isso, um dos motivos pelos quais nos parece intempestivo problematizar as avaliações em larga escala no espaço da escola onde desenvolvemos a pesquisa é que elas, de certa forma, se colocam como algo dado, ou seja, como uma das "verdades" da educação. Como se percebe nas manifestações 


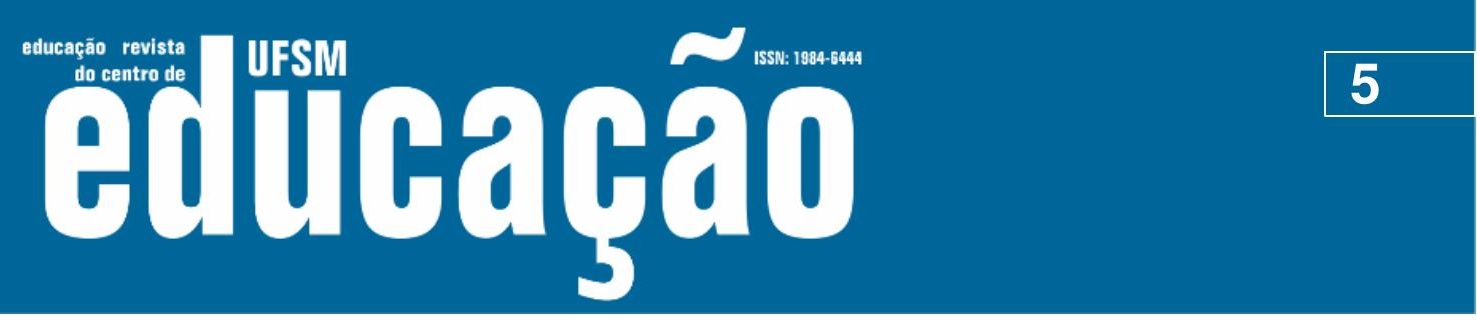

ISSN: 1984-6444 | http://dx.doi.org/10.5902/1984644435702

[...] não há verdade que, antes de ser uma verdade, não seja a efetivação de um sentido ou a realização de um valor. A verdade como conceito é totalmente indeterminada. Tudo depende do valor e do sentido do que pensamos. Temos sempre as verdades que merecemos em função do sentido daquilo que concebemos, do valor daquilo em que acreditamos. [...] A verdade de um pensamento deve ser interpretada e avaliada segundo as forças ou a potência que o determinam a pensar, e a pensar isso de preferência àquilo (DELEUZE, 2018, p. 134).

Se a verdade de alguma coisa, conforme Deleuze (2018), tem a ver com o sentido - entendido como a relação dessa coisa com a força que se apodera dela - e tem a ver com valor - entendido como a hierarquia das forças que se expressam na coisa -, então, a verdade não é "uma criatura bonachona e que gosta de suas comodidades, que dá sem cessar a todos os poderes estabelecidos a segurança de que jamais causará a alguém o menor embaraço, pois, afinal de contas, ela é apenas a ciência pura" (DELEUZE, 2018, p.134). O autor diz que devemos sempre perguntar que forças se escondem no pensamento daquela verdade, ou seja, perguntar sempre qual é o sentido e qual é o valor da verdade.

Se a imagem dogmática do pensamento - que, conforme Machado (2009), é ortodoxa, metafísica, moral, transcendente - empenha-se em ocultar o jogo de forças, ou seja, o sentido e o valor das políticas de avaliação em larga escala, teóricos como Esteban (2008; 2012; 2014), Silva (2007), Pacheco e Marques (2014) e Hypólito e Ivo (2013) aproximam-se de um pensamento sem imagem, que Machado (2009) caracteriza como um espaço pluralista, heterodoxo, ontológico, ético, trágico, imanente, e empenham-se em entender esse jogo tornando visíveis tais forças. Pensamos com Deleuze (2018) que a tarefa da filosofia e, neste caso, também da educação consiste em "incomodar a besteira, faz[er] da besteira algo vergonhoso" (DELEUZE, 2018, p. 136).

Aquilo que o filósofo francês denomina de besteira não consiste em um equívoco, ilusão, erro, distração, mas em algo que circula no contexto escolar e restringe/dificulta as conexões de professores/as e alunos/as por instaurar uma imagem dogmática de pensamento e nela se sustentar, como parecem ser as relações de poder das políticas de avaliação nacional. Por isso, ao analisar o formato que as avaliações em larga escala assumiram no país, Esteban (2014) questiona a qualidade pretendida e a proposta pedagógica anunciada em um procedimento tão redutor. $A$ 


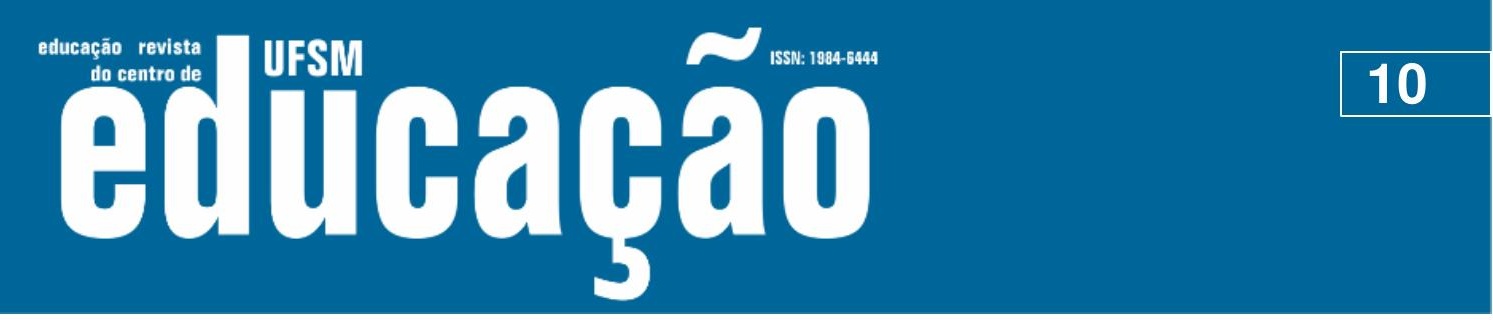

ISSN: 1984-6444 | http://dx.doi.org/10.5902/1984644435702

\section{As avaliações em larga escala - entre poder e resistência}

Historicamente, o outro da educação, para Skliar (2003), foi sempre um outro que devia ser anulado, apagado. Contudo, o autor ressalta que "as atuais reformas pedagógicas parecem já não suportar o abandono, a distância, o descontrole. E se dirigem à captura maciça do outro para que a escola fique ainda mais satisfeita com sua missão de possuir tudo dentro de seu próprio ventre" (SKLIAR, 2003, p. 27). Para esse fim, as avaliações em larga escala muito contribuem, pois se orientam pela lógica do controle e tendem a excluir os próprios sujeitos dos processos de avaliação. Nessa lógica, os sujeitos avaliados "têm quase sempre um estatuto epistemológico, pedagógico e ético de um 'objeto' extrínseco ao sujeito avaliador e à avaliação propriamente dita" (MACHADO, 2013, p. 23), e é esse pressuposto que torna possível reduzir o juízo avaliativo a uma mera "medida".

A análise que Foucault (1996) faz da técnica do exame, em sua obra Vigiar e Punir, ajuda-nos a compreender as avaliações nacionais como um dispositivo do poder disciplinar. Segundo o autor, o exame "é um controle normalizante, uma vigilância que permite qualificar, classificar e punir" (FOUCAULT, 1996, p. 164) cada individualidade. Avalia-se uma instituição disciplinar - no caso, a escola - para extrair de todos/as os/as alunos/as um conhecimento com a finalidade de produzir diagnósticos; com a finalidade de traduzir esse conhecimento em números, que serão interpretados, qualificando ou desqualificando conhecimentos, sujeitos e instituições; para estipular até onde determinado/a aluno/a pode chegar e o que é válido nele/a investir, tendo em vista produzir prognósticos. Desse modo, pelas avaliações, constrói-se uma verdade sobre os sujeitos/alunos/as, e essa verdade tem efeitos de subjetivação, pois imprime características, aponta limites e diz sobre as possibilidades de cada individualidade. Por isso, Esteban (2012) afirma que a técnica do exame - ou as avaliações nacionais - se constitui "pela relação hierárquica que dá visibilidade, vigia e sanciona os sujeitos para normalizá-los, submetê-los e direcionar seu comportamento e seu rendimento de acordo com as demandas do modelo hegemônico de sociedade" (ESTEBAN, 2012, p. 579). 


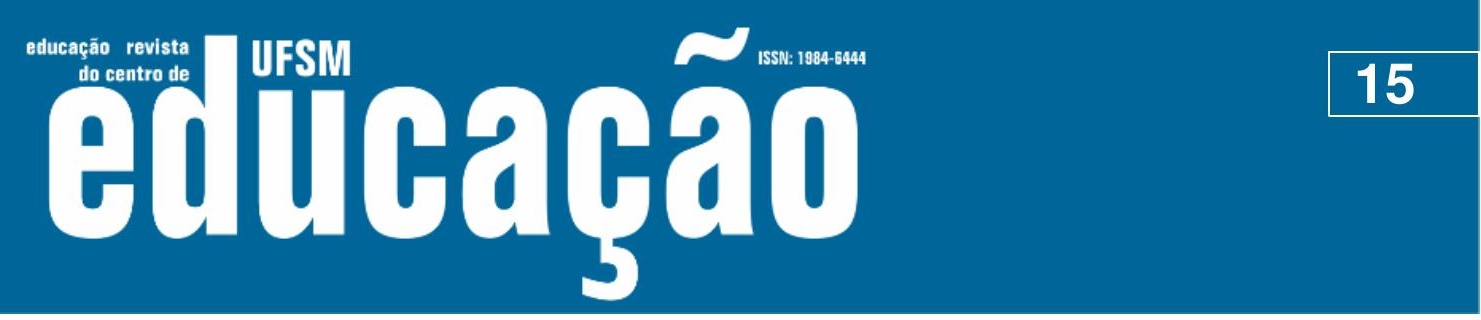

ISSN: 1984-6444 | http://dx.doi.org/10.5902/1984644435702

Que não há relações de poder sem resistências; que estas são tão mais reais e eficazes quanto mais se formem ali mesmo onde se exercem as relações de poder; a resistência ao poder não tem que vir de fora para ser real, mas ela não é pega na armadilha porque ela é a compatriota do poder. Ela existe tanto mais quanto ela esteja ali onde está o poder; ela é, portanto, como ele, múltipla e integrável a estratégias globais (FOUCAULT, 2015, p.244).

Se as práticas de resistência possuem as mesmas características que as relações de poder - são móveis, produtivas, inventivas - e se não representam uma libertação em relação ao poder a partir de um lugar de exterioridade deste, mas ocorrem ali mesmo onde há relações de poder, então, entendemos que as resistências que professores/as e alunos/as desenvolvem na escola podem fundar novas relações de poder, assim como novas relações de poder também podem dar origem a novas formas de resistência.

Nesse sentido, destacamos a potência das críticas/resistências que o professor Mateus, o professor José e a professora Isabel tecem a esses modelos avaliativos. O professor Mateus diz ter restrições a esse sistema: "é um sistema puramente estatístico. Eu não acho que é possível mostrar que uma escola é boa para o Brasil inteiro - alcançando metas numerais. Eu, particularmente, não acho". O professor José mostra-se reticente em relação às avaliações em larga escala; segundo ele, "a prova é um demonstrativo legal, só que, na verdade, o cotidiano da escola não é medido por essa prova [...]. É claro que a gente está entre os primeiros lugares aqui porque o que houve, aos meus olhos, é que os alunos são doutrinados para isso". A professora Isabel ressalta que essas avaliações não contemplam e não valorizam os conhecimentos contextuais; ela diz que as avaliações em larga escala "fazem um apanhado de questões no âmbito geral, e aplica-se sem saber a realidade daquela escola, daquela turma".

Esses/as professores/as, ao problematizarem a quantificação e a "doutrinação" dos/as alunos/as e ao perceberem/falarem que as avaliações padronizadas não valorizam os conhecimentos contextuais e não dizem sobre o que a escola faz e o que os/as alunos/as sabem, mostram movimentos de resistência e tornam o ambiente escolar um local de tensões, fissuras, desestabilidade - um espaço onde outras configurações de força estão sempre em constituição. Na medida em que as relações de poder das políticas de avaliação nacional estão disseminadas no contexto da 


\section{تilfoarẫ}

ISSN: 1984-6444 | http://dx.doi.org/10.5902/1984644435702

os discursos educacionais, inclusive aqueles que sustentam as políticas de avaliação em larga escala e sua pretensão de medir a qualidade da educação por meio de processos de homogeneização. É preciso inventar, para a educação, outra concepção de pensamento, abandonando sua imagem ou dando-Ihe outra. Isso significa dizer que é preciso "pensar de outro modo nossa relação com o outro da educação, que não requer outra coisa além de arriscar-se a pensar de outra maneira a mesmidade" (LARA, 2003, p. 15). Assim, podemos potencializar outros processos/percursos educacionais, na medida em que tomamos como referência outra concepção de qualidade da educação, que nos remete, conforme Esteban (2014), a movimentos de colaboração, de crítica, de ações coletivas, de concepções de educação que se sustentem no reconhecimento da positividade da diferença.

Apesar de termos destacado que as práticas de resistência que os/as professores/as e alunos/as desenvolvem no contexto das relações de poder das avaliações em larga escala instauram fissuras, abalos nos modos de educação estabelecidos - e isso não deixa dúvida de que outras configurações de força, outras relações de poder circulam no contexto da escola onde desenvolvemos a pesquisa um dos grandes desafios consiste em encontrar mecanismos para ampliar cada vez mais as ressonâncias desses abalos, dessas fissuras.

É preciso que a intempestividade de nossas análises e de nossas ações se multipliquem cada vez mais e possibilitem liberar as avaliações, o currículo e a constituição dos sujeitos das forças que, conforme Pelbart (2013), buscam dizimar cotidianamente modos de vida "menores", minoritários, "não apenas mais frágeis, precários, vulneráveis (pobres, loucos, autistas), mas também mais hesitantes, dissidentes, ora tradicionais (povos da floresta), ora, ao contrário, ainda nascentes, tateantes ou mesmo experimentais (por vir, por descobrir, por inventar)" (PELBART, 2013, p. 404). É preciso encontrar mecanismos para instaurar processos educacionais que potencializem as singularidades dos múltiplos modos de existência. 


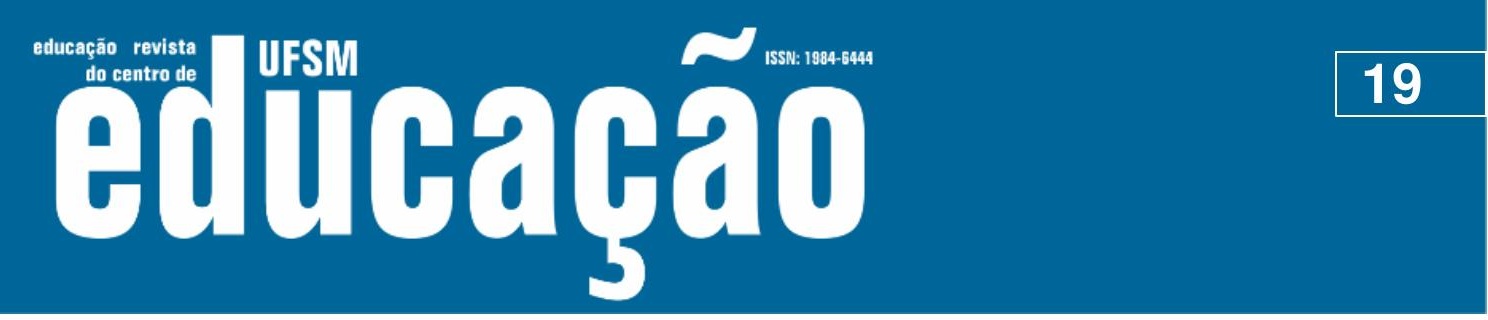

ISSN: 1984-6444 | http://dx.doi.org/10.5902/1984644435702

\section{Referências}

DELEUZE, Gilles. PARNET, Claire. Diálogos. São Paulo: Escuta, 1998.

DELEUZE, Gilles. Nietzsche e a Filosofia. São Paulo: n-1 edições, 2018.

DELEUZE, Gilles. Conversações. 3º ed. São Paulo: Editora 34, 2013.

DUARTE, André. Biopolítica e resistência: o legado de Michel Foucault. In: RAGO, Margareth; VEIGA-NETO, Alfredo (Orgs.). Figuras de Foucault. $2^{\mathrm{a}}$ ed. Belo Horizonte: Autêntica, 2008. p. 45-55.

DUARTE, André. Foucault $e$ as novas figuras da biopolítica: o fascismo contemporâneo. In: RAGO, Margareth; VEIGA-NETO, Alfredo (Orgs.). Para uma vida não fascista. Belo Horizonte: Autêntica, 2015. p. 35-50.

ESTEBAN, Maria Teresa. A avaliação no cotidiano escolar. In: ESTEBAN, Maria Teresa (Org.). Avaliação: uma prática em busca de novos sentidos. $5^{\circ}$ ed. Petrópolis: DP et Alii, 2008. p. 7-23.

ESTEBAN, Maria Teresa. Encontros e desencontros no cotidiano escolar. Revista Teias, v. 14, no 33, p. 168-175, 2012.

ESTEBAN, Maria Tereza. A negação do direito à diferença no cotidiano escolar. Avaliação, Campinas; Sorocaba, SP, v. 19, n. 2, p. 463-486, jul. 2014.

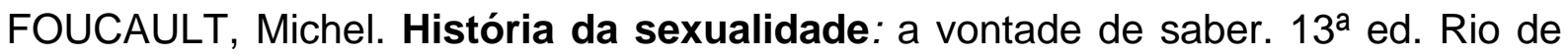
Janeiro: Edições Graal, 1988.

FOUCAULT, Michel. Em defesa da Sociedade. São Paulo: Martins Fontes, 1999.

FOUCAULT, Michel. Microfísica do poder. 15 ${ }^{\mathrm{a}}$ ed. Rio de Janeiro: Edições Graal, 2000.

FOUCAULT, Michel. Nascimento da biopolítica. São Paulo: Martins Fontes, 2008.

FOUCAULT, Michel. Vigiar e punir. 14ª ed. Petrópolis: Vozes, 1996.

FOUCAULT, Michel. Poderes e estratégias. In: FOUCAULT, Michel. Ditos e Escritos IV: Estratégia, poder-saber. $3^{\underline{a}}$ ed. Rio de Janeiro: Forense Universitária, 2015. p. 236246.

HYPÓLITO, Álvaro Moreira; IVO, Andressa. Aita. Políticas curriculares e sistemas de avaliação: efeitos sobre o currículo. Revista E-Curriculum, no 11, v. 02, p. 376-392, agosto 2013.

LARA, Nuria Pérez de. Pensar muito além do que é dado, pensar a mesmidade a partir do outro que está em mim. In: SKLIAR, Carlos. Pedagogia (improvável) da diferença: e se o outro não estivesse aí? Rio de Janeiro: DP\&A, 2003. p. 11-15. 


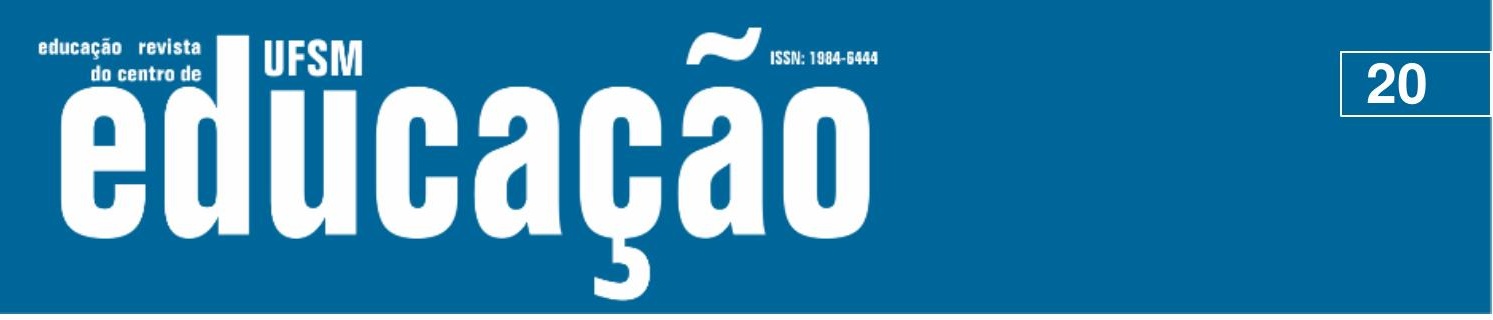

ISSN: 1984-6444 | http://dx.doi.org/10.5902/1984644435702

MACHADO, Eusébio André. Avaliar é ser sujeito ou sujeitar-se? Elementos para uma genealogia da avaliação. Portugal: Edições Pedago, 2013.

MACHADO, Roberto. Deleuze, a arte e a filosofia. Rio de Janeiro: Zahar, 2009.

PACHECO, José. Augusto. MARQUES, Micaela. Governamentalidade curricular: ação dos professores em contextos de avaliação externa. In: OLIVEIRA. Maria Rita. (Org.). Professor: formação, saberes e problemas. Porto: Porto Editora, 2014. p. 105136.

PAVAN, Ruth. Currículo, a construção das identidades de gênero e a formação de professores. Revista Contrapontos, vol.13, no2, p. 102-111, mai/ago 2013.

PELBART, Peter Pál. O avesso do niilismo: cartografias do esgotamento. São Paulo: n-1 edições, 2013.

SILVA, Tomaz Tadeu. Documentos de Identidade: uma introdução as teorias do currículo. 2ª . ed. Belo Horizonte: Autêntica, 2007.

SKLIAR, Carlos. Pedagogia (improvável) da diferença: e se o outro não estivesse aí? Rio de Janeiro: DP\&A, 2003.

SKLIAR, Carlos. Desobedecer a linguagem: educar. Belo Horizonte: Autêntica Editora, 2014.

TRAVERSINI, Clarice Salete. BELLO, Samuel Edmundo. López. O numerável, o mensurável e o auditável: estatística como tecnologia para governar. Educação e Realidade. 34(2), p. 135-152, mai/ago 2009.

TRAVERSINI, Clarice Salete. Currículo e avaliação na contemporaneidade: Há lugar para a diferença em tempos de imperativo dos números? In.: FAVACHO, André Marcio Picanço; PACHECO, José Augusto; SALES, Shirlei Rezende (Orgs.). Currículo: conhecimento e avaliação divergências e tensões. Curitiba: CRV, 2013. p.177- 187.

VEIGA-NETO, Alfredo. Coisas de governo. In: RAGO, Margareth; ORLANDI Luis Benedicto Lacerda; VEIGA-NETO, Alfredo (Orgs.). Imagens de Foucault e Deleuze: Ressonâncias nietzschianas. Rio de Janeiro: DP\&A, 2002. p. 13-34.

VEIGA-NETO, Alfredo. Educação e governamentalidade neoliberal: novos dispositivos, novas subjetividades. In: PORTOCARRERO, Vera; CASTELO BRANCO, Guilherme (Orgs.). Retratos de Foucault. Rio de Janeiro: NAU, 2000. p. 179-217.

\section{Correspondência}

Sirley Lizott Tedeschi - Universidade Estadual de Mato Grosso do Sul - Rod. Dourados/Itahum KM 12, Universitário, CEP 79804-970 - Dourados, Mato Grosso do Sul, Brasil. 


\section{Lism \\ 1SSN: $1984-6444$

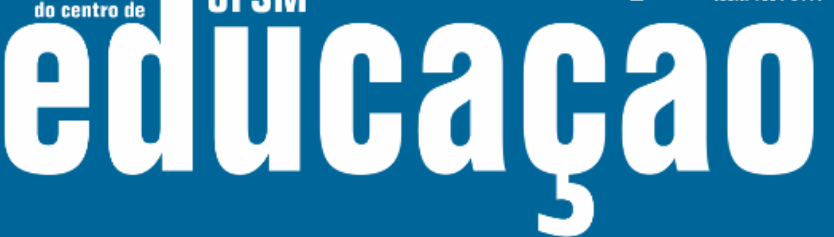

ISSN: 1984-6444 | http://dx.doi.org/10.5902/1984644435702

(C) $(1) \Theta$

This work is licensed under a Creative Commons Attribution-NonCommercial 4.0 International (CC BY-NC 4.0)

\section{Nota}

\footnotetext{
1 Veiga-Neto (2002) analisa o conceito de governo na obra de Michel Foucault e aponta que não podemos confundir governo - como uma instância governamental e administrativa - com a ação de governar. Para o autor, “o que se está grafando como ‘práticas de governo’ não são ações assumidas por um staff que ocupa uma posição central no Estado, mas são ações distribuídas microscopicamente pelo tecido social; por isso soa bem mais claro falarmos em "práticas de governamento"” (VEIGA-NETO, 2002, p. 21).
} 